paign with 30,000 posters to be sent to hospitals and doctors' surgeries reminding people that when they die, their kidneys could save other people's lives. But without a change in the law, any positive response will only cause frustration all round.

So the problem comes back to the doctors themselves, who have to make the most of the kidneys that come their way. One of the headaches here is defining the moment of death in the donor - a problem that has become even more difficult in recent months with the increasing use of ventilators. For a successful transplant, a kidney must be extracted within an hour of death and where the patient is being kept 'alive' artificially by ventilation the doctor (and in transplant cases, two doctors are required to cerify death) must decide when the brain has died and when the ventilator has passed the point at which it will invoke any involuntary response in the patient.

Anthony Barnes maintains that many doctors are siill only learning when to turn the ventilator off. Some, he says, do an injustice to relatives by allowing their patients to rot with a brain that is never going to work again. "And the kidneys become roiten too," he says, "and that's an awful waste." And to rub in the dilemma facing doctors, the coroner at the Birmingham inquest involving $\mathrm{Mr}$ Barnes, told the jury that

THE pay of government scientists in Britain will continue to be determined by reference to that of scientists in industry rather than by comparisons with other branches of the Civil Service if the recommendations of the Pay Board on Science Group pay are accepted as policy.

About 16,000 members of the group are affected by the report of the board, which appeared after a protracted dispute over the criteria for determining their salaries. The scientists, represented by the Institution of Professional Civil Servants (IPCS), were loth to accept a pay research exercise referring to the rates of scientists in industry because, it was argued, the government was such a large scale employer that industrial rates were themselves determined by the level of pay in the public sector, and so any comparison would be prey to an illogical circularity.

The report says, however, that the process of pay research is not invalidated by these special circumstances, and that they can be taken into account, either by the Pay Research Unit (PRU) in making comparisons or where this is not possible, by the parties involved in negotiation.

The IPCS had pointed out in evidence to the board that scientists

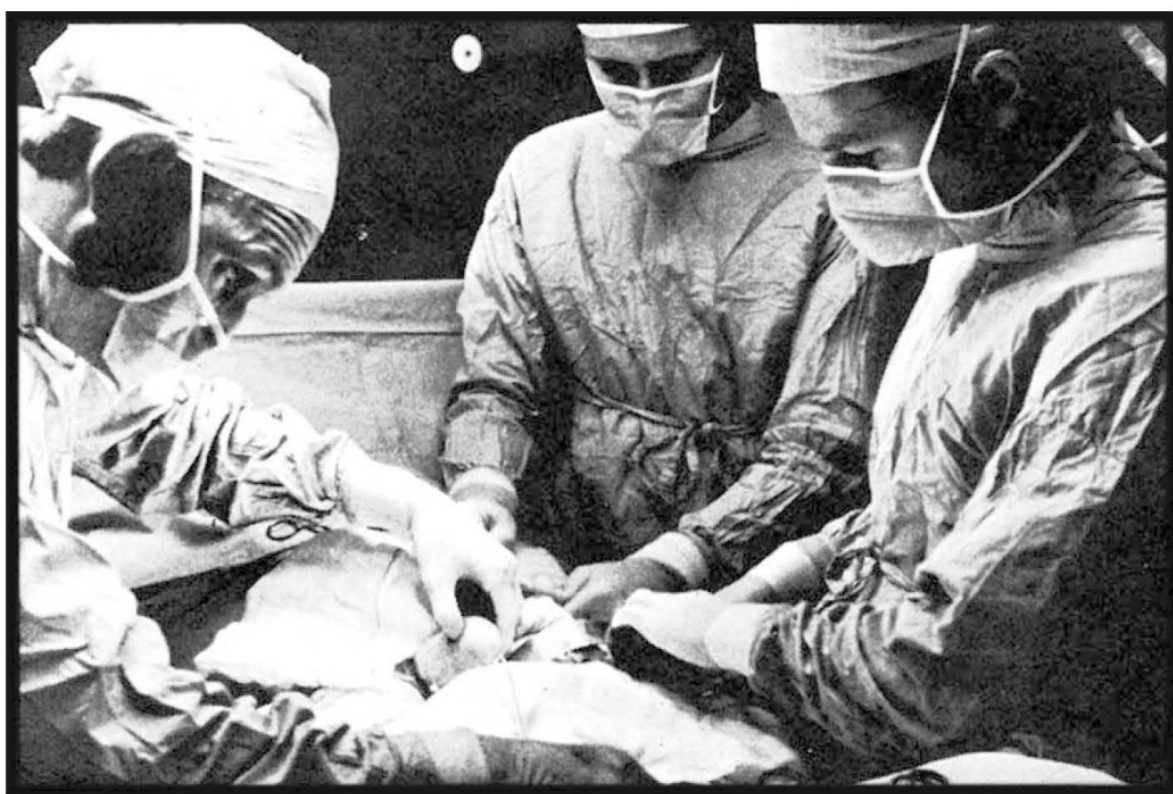

A patient receives a transplant kidney at Guy's Hospital, London

there was "considerable dissention among pathologists he had quesiioned about when a person was dead".

Dostors abroad involved in kidney transplants already have fewer problems. In France, and in some parts of the United States, brain death is accepted as a clear index of death, which means that much fresher kidneys are available from donors who are still breathing. (I $\hat{\imath}$ also, of course, means

\section{Pay Board reports on scientists}

had not had a substantive pay review since January 1971, when there was a measure of parity between their rates and those of comparable grades in the Civil Service Administration Group. By January this year the scientists had fallen behind, at the scale maxima, by as much as $£ 880$ at Principal Scientific Officer (PSO) level, and $£ 731$ at Higher Scientific Officer level.

According to the IPCS new rates should have been determined, according to a principle of the Priestley Commission, by internal relativities, using the Professional and Technology Group as a comparison, rather than the Administration Group, as in the past. But the only point at which the Pay Board leaned towards internal relativities was in its suggestion that PSO rates should at both ends of the scale (currently $£ 3,715$ and $£ 4,895$ ) be no more than $5 \%$ away from the rates for their counterparts in the administrative grades. As a corollary, the report recommends that the maximum of the Senior Scientific Officer scale (now $£ 3,895$ ) should be adjusted that many patients are spared lives as cabbages.) The Americans also have the Uniform Anatomical Gift Act which has made donor cards legal documents.

And in Scandinavia the law says a doctor can take what he likes from a corpse, with no questions asked. Clearly, legislation along these lines would make life easier for transplant surgeons working in Britain. if pay research does not produce an appropriate differential with the minimum of the PSO scale.

Both these adjustments would take into account what the report calls the "unquantifiable" factors of individual merit and the differing career pattern of government scientists, who tend to go on working in research and development long after the age at which their industrial counterparts have moved on to greener pastures. About 5,500 scientists would be affected by this suggestion.

The remaining 10,500 members of the Science Group will have to be content with pay research, although there is a recommendation that procedures for the exercise should be reviewed jointly by the scientists, the Civil Service Department and the PRU.

The IPCS said it was "severely disapointed" with these formal recommendations, which would take a long time to implement (January 1976 has been suggested as the earliest date by which the exercise could even get under way). But the union adds that, given goodwill on the part of the government, there is no reason why an agreement should not be reached and it has entered an interim claim, based again on internal relativities. 